\title{
Influence of thermodynamic disfigurement on the convective heat transfer of solar greenhouse
}

\author{
Yachen Sun ${ }^{1 \dagger}$, Yanfei $\mathrm{Cao}^{1 \dagger}$, Haotian Wang ${ }^{1}$, Changji Zhou ${ }^{2}$, Jinxin Xiao ${ }^{1}$, Chengyao Jiang ${ }^{1}$, \\ Jianming $\mathrm{Li}^{1}$, Encai Bao ${ }^{3 *}$, Zhirong Zou ${ }^{1 *}$ \\ (1. Key Laboratory of Protected Horticultural Engineering in Northwest, Ministry of Agriculture and Rural Affairs, Department of \\ Horticulture, Northwest A\&F University, Yangling 712100, Shaanxi, China; \\ 2. Academy of Agricultural Planning and Engineering, Ministry of Agriculture and Rural Affairs, Beijing 100125, China; \\ 3. Institute of Agricultural Facilities and Equipment, Jiangsu Academy of Agricultural Sciences, Key Laboratory of Protected Agriculture \\ Engineering in the Middle and Lower Reaches of Yangtze River, Ministry of Agriculture and Rural Affairs, Nanjing 210014, China)
}

\begin{abstract}
Solar greenhouse is a typical greenhouse without any additional heating system, which has developed rapidly in Northern China. However, due to the construction quality, management methods, especially the long-term use and other factors, there are usually different degrees of thermodynamic disfigurements in the envelop enclosure of solar greenhouse. The purpose of this study was to investigate the influences of thermodynamic disfigurement on the temperature distribution and convective heat transfer of solar greenhouse. In this study, the east and west compartments of a typical solar greenhouse which is located in Yangling, China $\left(108^{\circ} 4^{\prime} \mathrm{E}, 34^{\circ} 16^{\prime} \mathrm{N}\right)$ were tested. The air temperature of each compartment was collected using temperature recorders, and the thermal infrared images of different compartment envelopes were obtained by a thermal infrared imager on a typical cloudy day. Convective heat transfer coefficients and heat flux densities of different compartment envelopes in the solar greenhouse were calculated. The results showed that the temperature difference can be displayed in the thermal infrared images of compartment envelopes, the surface temperature of the front roof was the lowest, followed by the back roof, the wall surface temperature was the highest. The minimum average surface temperature of the front roof in the eastern compartment was only $3.8^{\circ} \mathrm{C}$, which was $6.8^{\circ} \mathrm{C}$ and $9.2^{\circ} \mathrm{C}$ lower than the average surface temperature of the back roof and back wall, respectively. The surface average temperature of thermodynamic disfigurements located at the bottom of the south side in the front roof of the eastern compartment, whose area accounted for $16.5 \%$ of the total front roof in the eastern compartment, was only $5.4^{\circ} \mathrm{C}$. Compared with non-thermodynamic disfigurement, the average convective heat transfer coefficient and heat flux density of thermodynamic disfigurements in the front roof of the eastern compartment were increased by $20.3 \%$ and $110.3 \%$, respectively. The average air temperature in the eastern compartment was $3.5^{\circ} \mathrm{C}$ lower than the average air temperature in the western compartment of the solar greenhouse. Construction of brick wall at the bottom of the south side of the front roof in the solar greenhouse helped to increase the inner surface temperature of the front roof, with an average temperature rise of $6.2^{\circ} \mathrm{C}$, and reduce the area of thermodynamic disfigurement, which only accounted for $2.6 \%$ of the total front roof in the western compartment. The average surface temperature of thermodynamic disfigurements mainly caused by the entry and exit door in the wall of the eastern compartment was only $9.8^{\circ} \mathrm{C}$, which was lower $3.2^{\circ} \mathrm{C}$ than the average temperature of non-thermodynamic disfigurement of the wall. Thermodynamic disfigurement helped to increase heat loss. The weighted average proportion of thermodynamic disfigurement in the western compartment was $2.1 \%$, while that of thermodynamic disfigurement in the eastern compartment was $10.7 \%$. The thermal insulation performance of the western compartment envelope in the solar greenhouse was better than that of the eastern compartment envelope.

Keywords: solar greenhouse, thermodynamic disfigurement, convective heat transfer, thermal infrared image DOI: $10.25165 /$ j.ijabe.20201304.5397
\end{abstract}

Citation: Sun Y C, Cao Y F, Wang H T, Zhou C J, Xiao J X, Jiang C Y, et al. Influence of thermodynamic disfigurement on the convective heat transfer of solar greenhouse. Int J Agric \& Biol Eng, 2020; 13(4): 55-60.

\section{Introduction}

The solar greenhouse is a typical horticultural installation with

Received date: 2019-09-15 Accepted date: 2019-11-03

Biographies: Yachen Sun, $\mathrm{PhD}$ candidate, research interests: facility horticulture, Email: sunyachen1993@163.com; Yanfei Cao, PhD, Lecturer, research interests: greenhouse structure optimization, Email: caoyanfei@nwsuaf.edu.cn; Haotian Wang, MS candidate, research interests: facility horticulture engineering, Email: ssyywht@nwafu.edu.cn; Changji Zhou, PhD, Researcher, research interests: facility horticulture, Email: zhoucj@facaae.com; Jinxin Xiao, $\mathrm{PhD}$ candidate, research interests: facility horticulture engineering, Email: jinxinxiao1994@163.com; Chengyao Jiang, PhD, Lecturer, research interests: regulation of greenhouse light environment, Email: catherinejiang@nwafu.edu.cn; regional features in China. It has a much more favorable cost performance relative to the multi-span greenhouse and much better hibernating ability than the plastic greenhouse, and thus is widely

Jianming Li, PhD, Professor, research interests: facility horticulture, Email: lijianming66@163.com.

$\dagger$ These authors contribute equally to this research.

*Corresponding author: Encai Bao, PhD, Assistant Researcher, research interests: facility horticulture engineering. Institute of Agricultural Facilities and Equipment, Jiangsu Academy of Agricultural Science, Nanjing 210014, China. Tel: +86-17768103527, Email: baoencai1990@163.com; Zhirong Zou, $\mathrm{PhD}$, Professor, research interests: facility horticulture. Department of Horticulture, Northwest A\&F University, Yangling 712100, Shaanxi, China. Tel: +86-13991124991, Email: zouzhirong2005@163.com. 
built in Northern China ${ }^{[1,2]}$. According to the statistical data from the Department of agricultural mechanization administration, Ministry of agriculture, China, there are $697000 \mathrm{hm}^{2}$ of solar greenhouses in China. Thermal insulation is the crucial work in building greenhouses, and there had been amounts of investigations focus on this issue, including the design of heat-insulation wall ${ }^{[3-7]}$, testing of insulation performance ${ }^{[8,9]}$, thermal environment dynamic simulation of greenhouse ${ }^{[10-12]}$, and thermal parameters of building material.

During the production practice, because of the construction quality problems, the breakage of thermal insulation materials and the deficient management, the envelop enclosure of the greenhouse usually has thermodynamic disfigurement to some extent. In addition, the quantity and area of these disfigurements will increase as the use of the greenhouse, leading to a remarkable decrease in their functional performance. Due to the high cost of building a new greenhouse, it is necessary and of great importance to find practicable approaches and instruments to pinpoint the regions with thermodynamic disfigurement, and thus bring down the costs of old greenhouses rehabilitation.

It had been well documented how to accessing the insulation performance of the greenhouses with different spans ${ }^{[13]}$, wall materials $^{[14]}$, thermal insulation system $^{[15]}$ according to the determination of indoor air temperature. These experiences can be used as the basis for greenhouse design and construction. However, there has been no systemic method to comprehensively and accurately analyze the reason causing the differences in the thermal insulation performance among greenhouses.

Infrared imaging techniques can make the surface heat distribution (including the temperature and its differences) of the objects visible by showing them as grayscale differences or false color forms. This proven non-destructive testing approach has been widely used in the constructional ${ }^{[16,17]}$, electrical ${ }^{[18]}$ and healthcare industry ${ }^{[19]}$. Hence, using the thermal mapper is a promising approach to quickly detect the thermodynamic disfigurement regions in the envelop enclosure, and to analyzing and calculating the impacts of these disfigurements on the heat flux in the greenhouse, and thus guiding the reconstruction and building of solar greenhouse. This technique had been used for detecting the thermodynamic disfigurement of the envelope of building ${ }^{[20,21]}$, or judging the defects in pipeline insulation structure and their impacts on the heat dissipation of pipes ${ }^{[22,23]}$. These investigations provide references for grasping the methods evaluating the envelope structure performance of solar greenhouse. In the present study, thermal infrared imager was used for detecting the surface temperature of the envelop enclosure of a typical solar greenhouse in Yangling, China, the convective heat transfer coefficient and heat flux density of the thermodynamic disfigurement regions was calculated, and the thermal insulation performance of the envelope was assessed.

\section{Calculating of the thermodynamic disfigurement of the greenhouse envelop enclosure}

A thermal infrared imager uses the thermal radiation of the target object to form images, that is, measuring the temperature of each point on the surface of the object at the same time, and intuitively display the temperature field of that in the form of images. According to the analysis of the temperature difference in the thermal infrared image, the potential defects in the internal insulation of the greenhouse envelope can be found.
According to the methods calculating the thermal defects of building insulation, the regions with $(0.5-1.0)^{\circ} \mathrm{C}$ temperature differences with other regions were defined as thermodynamic disfigurement regions. As the surface temperature of envelop enclosure is greatly influenced by the material and thickness of the insulation layer, it is hard to reflect the average temperature of the whole envelop enclosure with the temperature of one of the regions without thermodynamic disfigurement. Hence, before the judgment of the thermodynamic disfigurement regions, the envelop enclosure was divided into 3 parts according to the material used, including a front roof, back roof and back wall (Figure 1). When judging the thermodynamic disfigurement regions, the temperature of the given region was compared with the average temperature of the other regions of the same part of the envelop enclosure. Then the area of the defected region was calculated using the FLIR Tools and LabVIEW13.0 according to the methods in literature ${ }^{[24]}$. In the present study, the regions with more than $1.0^{\circ} \mathrm{C}$ lower temperature than the average temperature of the other regions from the same part were seen as thermodynamic disfigurement regions.

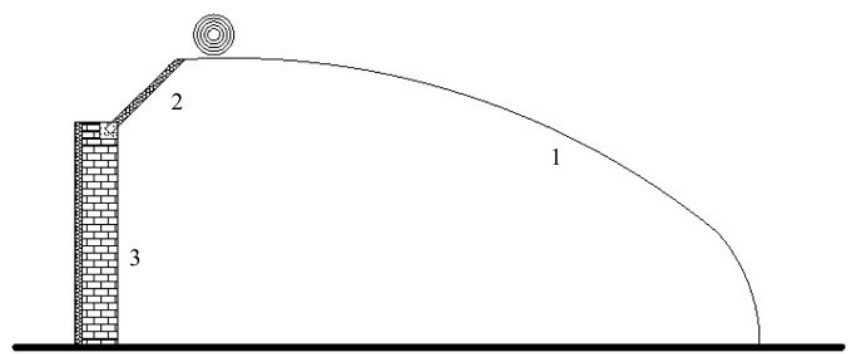

1. Front roof 2. Back roof 3. Back wall

Figure 1 Schematic diagram of solar greenhouse

According to the determination results, the relative area of the thermodynamic disfigurement regions in part $i$ of the envelop enclosure $\Psi_{i}$ was calculated with Equation (1):

$$
\Psi_{i}=\frac{\sum A_{\text {in }}}{A_{i}}
$$

where, $A_{i n}$ is the area of the $n$th thermodynamic disfigurement region in part $i, \mathrm{~m}^{2} ; A_{i}$ is the area of part $i$ of the envelop enclosure, $\mathrm{m}^{2}$.

The heat flux destiny of heat convection between the indoor air and the $n$th thermodynamic disfigurement region in part $i\left(q_{\text {in }}\right)$ was calculated with Equation (2):

$$
q_{\text {in }}=h_{\text {in }}\left|T_{2 i n}-T_{0}\right|
$$

where, $h_{i n}$ is the convective heat-transfer coefficient of the $n$th thermodynamic disfigurement region in part $i, \mathrm{~W} /\left(\mathrm{m}^{2} \cdot{ }^{\circ} \mathrm{C}\right) ; T_{2 i n}$ is the average temperature of it, ${ }^{\circ} \mathrm{C}$; while $T_{0}$ is the average air temperature in the greenhouse, ${ }^{\circ} \mathrm{C}$.

The weight of the thermosteresis of the thermodynamic disfigurement regions in the thermosteresis of the whole envelop enclosure $\left(\beta_{i}\right)$ was calculated with Equation (3):

$$
\beta_{i}=\frac{\sum q_{i n} A_{i n}}{\sum q_{i} A_{i}}
$$

The average temperature of the thermodynamic disfigurement regions in part $i$ of the envelop enclosure $\left(T_{2 i}\right)$ was calculated with Equation (4):

$$
T_{2 i}=\frac{\sum A_{i n} T_{2 i n}}{\sum A_{\text {in }}}
$$

The convective heat-transfer coefficient of the internal surface of the greenhouse covering material (front roof) $\left(h_{1 n}\right)$ was calculated with Equation (5) ${ }^{[9]}$ : 


$$
h_{1 n}=2.21 \Delta T_{1 n}^{0.33}
$$

where, $\Delta T_{1 n}$ is the differences between the average air temperature in the greenhouse and the average temperature of the $n$th thermodynamic disfigurement region of the internal surface of the greenhouse covering material, ${ }^{\circ} \mathrm{C}$.

The convective heat transfer coefficient of the internal surface of the back roof $\left(h_{2 n}\right)$ was calculated with Equation $(6)^{[23]}$ :

$$
h_{2 n}=1.86 \Delta T_{2 n}^{0.33}
$$

where, $\Delta T_{2 n}$ are the differences between the average air temperature in the greenhouse and the average temperature of the $n$th thermodynamic disfigurement region of the internal surface of the back roof, ${ }^{\circ} \mathrm{C}$.

The convective heat transfer coefficient of the internal surface

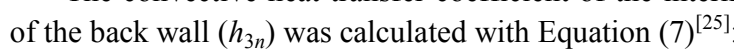

$$
h_{3 n}=1.86 \Delta T_{3 n}^{0.33}
$$

where, $\Delta T_{3 n}$ are the differences between the average air temperature in the greenhouse and the average temperature of the $n$th thermodynamic disfigurement region of the internal surface of the back wall, ${ }^{\circ} \mathrm{C}$.

\section{Materials and measuring point setting}

\subsection{Materials and instruments}

The experiment was conducted in the No. 1 solar greenhouse in Northwest A\&F University, Yangling, China in December 2018 (Figure 2). The length of the greenhouse is $50.0 \mathrm{~m}$, and the net span is $8.0 \mathrm{~m}$. The north wall (back wall) height is $2.2 \mathrm{~m}$, with a thickness of $1.0 \mathrm{~m}$, and a $10 \mathrm{~cm}$ thick polystyrene board. The ridge height of the greenhouse is $3.5 \mathrm{~m}$. The thickness of the east and west clay brick walls is $1.0 \mathrm{~m}$. The back slope width is $1.7 \mathrm{~m}$ and the material is colorbond-polystyrene. The front roof is covered by a heat preservation quilt. There is a $3.0 \mathrm{~m} \times 3.0 \mathrm{~m}$ auxiliary room in the east of the greenhouse. The greenhouse is divided into 5 compartments with colorbond-polystyrene board. According to the previous study ${ }^{[17]}$, the crevice of the door, south end of the front roof and damaged insulation material are the regions where heat loss is the most likely to happen, thus the west compartment (GH-E, the length is $16 \mathrm{~m}$ ) and east compartment (GH-W, the length is $8 \mathrm{~m}$ ) of the solar greenhouse are chosen for this study. In addition, a $115 \mathrm{~mm}$ thick, $0.5 \mathrm{~m}$ high brick wall was built at the inside south end of the west compartment. In this experiment, the entrance of the solar greenhouse was set on the east gable, while there was a brick wall at the same position on the west gable. As the door was one of the areas connecting the indoor and outdoor of the greenhouse, if the door was not tightly sealed, the cold air would enter into the greenhouse, leading to temperature differences between the east and west compartments of the greenhouse. However, it was not clear what was the temperature difference between the east and west compartments of the greenhouse, and if this temperature difference was entirely caused by the door or other thermodynamic disfigurements. In the preliminary experiments, it was found that the bottom of the front roof of the solar greenhouse could not be completely covered by the heat preservation quilt, and this area should be seen as a thermodynamic disfigurement. Thus, it should be clarified how does this area affect the indoor temperature of the solar greenhouse, and what measures could be taken to improve the thermodynamic disfigurement. For this purpose, a $0.5 \mathrm{~m}$ high brick wall was built on the south side of the solar greenhouse, and the effects of this measure were analyzed using a thermal infrared imager, with a view to providing a theoretical basis for actual production.
The $\mathrm{C} 2$ thermal infrared imager used for this study is produced by FLIR Ltd., America. Its wavelength coverage is $7.5-14 \mu \mathrm{m}$, with the field angle/minimum focal length of $41^{\circ} \times 31^{\circ} / 1.0 \mathrm{~m}$, a thermal sensitivity of $0.1^{\circ} \mathrm{C}$, a temperature measurement range of $-10^{\circ} \mathrm{C}$ to $150^{\circ} \mathrm{C}$ and a resolution of $320 \times 240$ pixels.

A GLM30 digital laser range finder of Bosch Ltd., Germany was used to determine the distance between the thermal infrared imager to the detected object, with an accuracy of $\pm 2 \mathrm{~mm}$.

A U23-001 temperature recorder of HOBO Ltd., America was used for temperature determination, the temperature measurement range of which is $-40^{\circ} \mathrm{C}$ to $70^{\circ} \mathrm{C}$, with an accuracy of $\pm 0.21^{\circ} \mathrm{C}$ and a resolution of $0.02^{\circ} \mathrm{C}$.

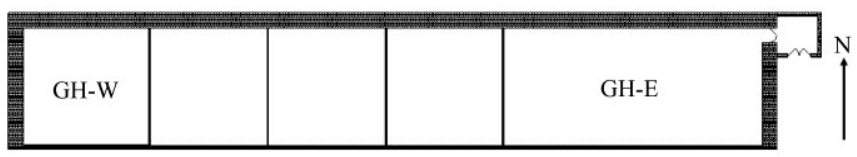

Note: GH-W represents the west compartment of the solar greenhouse, GH-E represents the east compartment of solar greenhouse

Figure 2 Plan of experimental solar greenhouse

\subsection{Methods}

The solar greenhouses are mainly used for winter production. Under the same external conditions, the indoor temperature at night is mainly affected by the heat released by the wall and the tightness (insulation performance) of the greenhouse. On cloudy days, the wall of solar greenhouse absorbs less solar radiation, the inside temperature difference of the greenhouse mainly comes from the tightness of the greenhouse, thus the experiment was conducted on cloudy days.

Besides, the heat loss of the solar greenhouse at night is mainly caused by the indoor and outdoor heat exchange through the thermodynamic disfigurement, the indoor temperature change is consistent with the temperature change of the surface of the envelope structure, while the convection heat transfer coefficient and the heat flux density change little.

Thus data were collected on a cloudy day (Dec. 10th, 2018) at 17:30-18:30, and the greenhouse was covered with heat preservation quilt.

Thermal infrared detection: The thermal infrared imager was fixed on a tripod, and the detection was conducted in the normal direction of the detected objects. The radiancy was set as 0.95 . The environmental temperature in the west compartment was set at $16^{\circ} \mathrm{C}$, while that in the east compartment was set at $12^{\circ} \mathrm{C}$. Before data collection, the thermal imager was automatically calibrated 3 times. The surface of the envelope is roughly tested firstly, and then the suspicious parts were tested in detail. At least 3 pictures were taken for the same part of the envelop enclosure, and the distance between imager and tested objects was recorded.

Temperature detection: the temperature recorder was installed in the center of each compartment with a height of $1.5 \mathrm{~m}$, and the time interval of temperature collection was set as $10 \mathrm{~min}$.

\section{Results and discussion}

\subsection{Thermal infrared images of solar greenhouse}

The thermal infrared images of the front roof, back roof and back wall of the west compartment were shown in Figure 3. It was found that there were significant differences among the color of the 3 parts of the envelop enclosure, indicating remarkable temperature differences. Specifically, the surface temperature of the front roof was the lowest while that of the back wall was the highest. Noticeably, there were obvious dark spots on the images of the front roof (Figure 3a) and back wall (Figure 3c), indicating 
that there were regions with significantly lower temperature. These mainly caused by the thermal bridge of the south end of the front roof and the blocked vent on the back wall. On the contrary, the surface temperature distribution of the back roof was relatively uniform (Figure 3b).

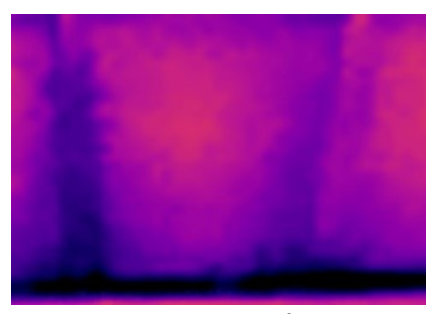

a. Front roof

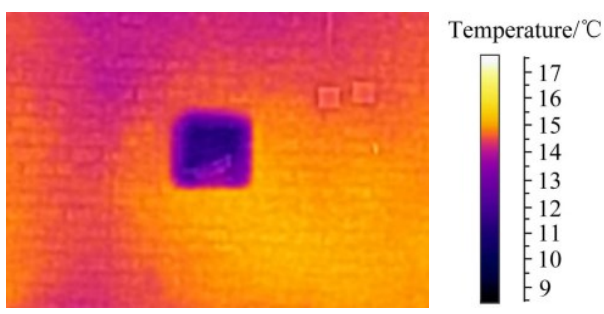

c. Back wall

b. Back roof

(1)

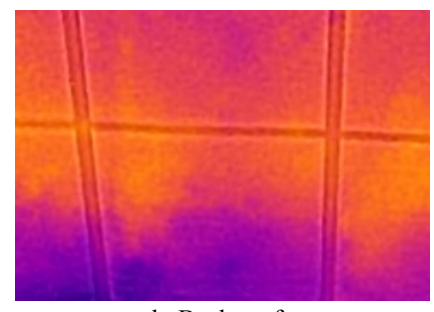

Figure 3 Thermal infrared image of solar greenhouse envelope

4.2 Comparison of the surface temperature of the different parts of the envelop enclosure

Typical thermal infrared images of different parts of the envelop enclosure were selected and the average temperature was used to show the surface temperature of the corresponding parts. The average temperature of air and envelop enclosure was given in Figure 4. Obviously, the temperature of the back wall was higher than those of the back roof and front roof. The front roof of the east compartment exhibited $6.8^{\circ} \mathrm{C}$ and $9.2^{\circ} \mathrm{C}$ lower temperature than the back roof and back wall (Figure 4a), while that of the west compartment exhibited $3.9^{\circ} \mathrm{C}$ and $5.0^{\circ} \mathrm{C}$ lower temperature than back roof and back wall, respectively (Figure $4 b$ ).

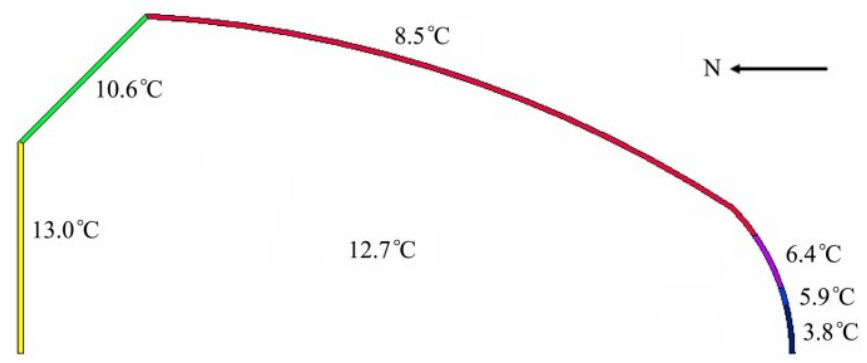

a. East compartment envelope

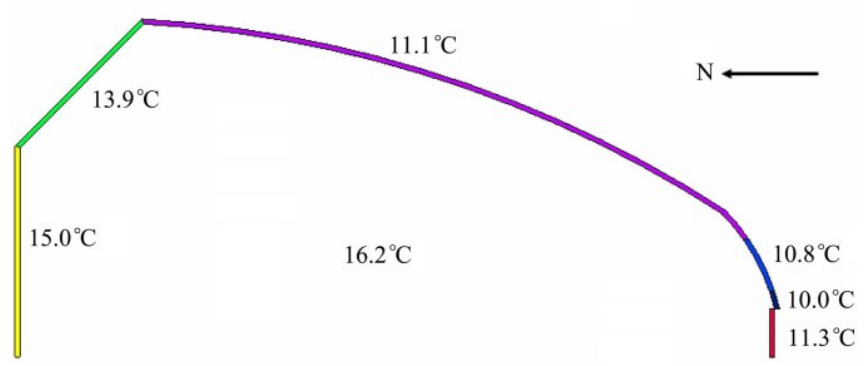

b. West compartment envelope

Figure 4 Average air temperature and average temperature distribution of solar greenhouse envelope

East compartment exhibited $3.5^{\circ} \mathrm{C}$ lower average air temperature than the west compartment, and the average temperature of their envelop enclosure exhibited similar characteristics. The front roof of the east compartment exhibited $6.2^{\circ} \mathrm{C}$ lower temperature than that of the west compartment, this should be attributed to the inside wall built in the south end of the front roof of the west compartment, indicating that to build a brick wall inside the south end was helpful to increase the surface temperature of the front roof. Besides, the average surface temperature of the back roof and back wall of the east compartment were $3.3^{\circ} \mathrm{C}$ and $2.0^{\circ} \mathrm{C}$ lower than those of the west compartment, respectively.

The back wall of the east compartment exhibited significant higher average surface temperature than air, while that of the west compartment exhibited opposing situation, indicating that the back wall of the east compartment was already transferring heat into the air, that was, it exhibited exothermic state earlier than that of the west compartment.

4.3 Area of thermodynamic disfigurement and convective heat transfer coefficient in solar greenhouse

According to the calculated results (Figure 1), there was thermodynamic disfigurement in $16.5 \%$ area of the front roof of the east compartment, the average surface temperature of these regions was only $5.4^{\circ} \mathrm{C}$, and showing $20.3 \%$ and $110.3 \%$ higher convective heat transfer coefficient and heat flux destiny than other regions. For the front roof of the west compartment, the area of thermodynamic disfigurement regions accounted for only $2.6 \%$, and showing only $6.7 \%$ and $29.7 \%$ higher convective heat transfer coefficient and heat flux destiny than defect-free regions.

There was no thermodynamic disfigurement region in the back roof of the east compartment, while there was thermodynamic disfigurement in $3.4 \%$ area of that of the west compartment, which shows $15.9 \%$ and $81.5 \%$ higher convective heat transfer coefficient and heat flux destiny than the defect-free regions, respectively.

For the east compartment, the thermodynamic disfigurement was mainly caused by the entrance, which accounted for $4.8 \%$ area of the wall, with an average temperature of $9.8^{\circ} \mathrm{C}$, an average convective heat transfer coefficient of $2.66 \mathrm{~W} /\left(\mathrm{m}^{2} \cdot{ }^{\circ} \mathrm{C}\right)$, and an average heat flux density of $7.84 \mathrm{~W} / \mathrm{m}^{2}$, which was much larger than the average convective heat transfer coefficient and heat flux density of the defect-free regions, because those regions had exhibited exothermic state. For the west compartment, the thermodynamic disfigurement regions accounted for $1.9 \%$ area of the wall, with an average temperature of $13.5^{\circ} \mathrm{C}$. Similarly, the average convective heat transfer coefficient and heat flux density of thermodynamic disfigurement regions were significantly higher than those of the defect-free regions.

Generally, thermodynamic disfigurement regions accounted for $10.7 \%$ and $2.1 \%$ area of the envelop enclosure of the east and west compartments, respectively. These regions aggravated the heat loss of the greenhouse.

\subsection{Comparison of heat loss in thermal defect area of solar greenhouse}

Front roof and back roof were the main heat-loss parts of solar greenhouse, and their heat-losses were calculated (Table 1). The entire heat dissipation of the roofs of the east compartment was larger than that of the west compartment. In addition, the heat loss of the thermodynamic disfigurement regions accounted for $27.37 \%$ of the entire heat loss of the east compartment, which also much higher than that of the west compartment, indicating that to strengthen the roof insulation measures is helpful to reduce the heat loss. 
Table 1 Area of thermodynamic disfigurement and convective heat transfer coefficient in solar greenhouse

\begin{tabular}{|c|c|c|c|c|c|c|c|c|c|}
\hline Compartment & Part & $\begin{array}{c}\text { Average } \\
\text { temperature of } \\
\text { thermodynamic } \\
\text { disfigurement } \\
{ }^{\circ} \mathrm{C}\end{array}$ & $\begin{array}{c}\text { Average } \\
\text { temperature of } \\
\text { defect-free } \\
\text { regions } /{ }^{\circ} \mathrm{C}\end{array}$ & $\begin{array}{c}\text { Area of } \\
\text { thermodynamic } \\
\text { disfigurement } \\
/ \mathrm{m}^{2}\end{array}$ & $\begin{array}{c}\text { Relative area of } \\
\text { thermodynamic } \\
\text { disfigurement } \\
/ \%\end{array}$ & $\begin{array}{l}\text { Average convective } \\
\text { heat transfer } \\
\text { coefficient of the } \\
\text { thermodynamic } \\
\text { disfigurement } \\
/ \mathrm{W} \cdot \mathrm{m}^{-2} \cdot{ }^{\circ} \mathrm{C}^{-1}\end{array}$ & $\begin{array}{c}\text { Average } \\
\text { convective } \\
\text { heat transfer } \\
\text { coefficient of the } \\
\text { defect-free regions } \\
/ \mathrm{W} \cdot \mathrm{m}^{-2} \cdot{ }^{\circ} \mathrm{C}^{-1}\end{array}$ & $\begin{array}{l}\text { Average heat flux } \\
\text { density of the } \\
\text { thermodynamic } \\
\text { disfigurement } \\
\quad / \mathrm{W} \cdot \mathrm{m}^{-2}\end{array}$ & $\begin{array}{l}\text { Average heat } \\
\text { flux density of } \\
\text { the defect-free } \\
\text { regions } \\
/ \mathrm{W} \cdot \mathrm{m}^{-2}\end{array}$ \\
\hline \multirow[b]{2}{*}{ GH-E } & Front roof & 5.4 & 8.5 & 21.76 & 16.5 & 4.27 & 3.55 & 31.35 & 14.90 \\
\hline & Back roof & -- & 10.6 & 0.00 & 0.0 & 0.00 & 2.82 & 0.00 & 5.93 \\
\hline \multirow{3}{*}{ GH-W } & Front roof & 10.0 & 11.1 & 1.60 & 2.6 & 4.04 & 3.78 & 25.02 & 19.30 \\
\hline & Back roof & 12.6 & 13.9 & 0.50 & 3.4 & 2.84 & 2.45 & 10.22 & 5.63 \\
\hline & Wall & 13.5 & 15.0 & 0.84 & 1.3 & 2.58 & 1.98 & 6.97 & 2.37 \\
\hline
\end{tabular}

Table 2 Calculation results of heat dissipation in thermodynamic disfigurement regions of roof of solar greenhouse

\begin{tabular}{|c|c|c|c|c|}
\hline Compartment of greenhouse & Part & $\begin{array}{l}\text { Heat dissipation of thermodynamic } \\
\text { disfigurement regions/W }\end{array}$ & $\begin{array}{c}\text { Heat dissipation of } \\
\text { defect-free regions } / \mathrm{W}\end{array}$ & $\begin{array}{l}\text { Proportion of the thermodynamic } \\
\text { disfigurement regions } / \%\end{array}$ \\
\hline GH-E & Front roof & 682.29 & 1641.03 & 29.37 \\
\hline \multirow{2}{*}{ GH-W } & Front roof & 40.03 & 1139.74 & 3.39 \\
\hline & Back roof & 5.11 & 79.95 & 6.01 \\
\hline
\end{tabular}

\section{Conclusions}

1) The front roof of the solar greenhouse had the lowest surface temperature, following the back roof, while the back wall had the highest surface temperature according to the infrared thermal mapping technique.

2) Thermodynamic disfigurement mainly occurred on the south side of the front roof, which accounted $16.5 \%$ area of the front roof, with an average surface temperature of $5.4^{\circ} \mathrm{C}$, and $20.3 \%$ and $110.3 \%$ higher average convective heat transfer coefficient and heat flux density than the defect-free regions. To build a low wall here could significantly decrease the area of thermodynamic disfigurement regions.

3) The entrance was the main thermodynamic disfigurement region of the wall, its average temperature was only $9.8^{\circ} \mathrm{C}$, which was $3.2^{\circ} \mathrm{C}$ lower than the defect-free regions.

\section{Acknowledgements}

This research was financially supported by Shaanxi Provincial Key Research and Development Program (Grant No. 2019TSLNY01-03), National Natural Science Foundation of China (31901420), Shaanxi Science and Technology Plan Program (2019FP-023).

\section{[References]}

[1] Xu F, Ma C W, Qu M, Liu Y, Gong B B, Zhang J Y, et al. Investigation and assessment on microclimate environment of solar greenhouse in North China. Chinese Journal of Agrometeorology, 2014; 35(1): 17-25. (in Chinese)

[2] Wei X M, Zhou C J, Cao N, Sheng B Y, Chen S Y, Lu S W. Evolution of structure and performance of Chinese solar greenhouse. Jiangsu Journal of Agricultural Sciences, 2012; 28(4): 855-860. (in Chinese)

[3] Sun Z P, Huang W Y, Li T L, Tong X J, Bai Y K, Ma J. Light and temperature performance of energy-saving solar greenhouse assembled with color plate. Transactions of the CSAE, 2013; 29(19): 159-167. (in Chinese)

[4] Qiu Z H, Song M J, Wang J Q, Zhang X B, Liu H, Meng T N, et al. Experiment effect of application to new assembly type solar double effect greenhouse. Transactions of the CSAE, 2014; 30(19): 232-239. (in Chinese)

[5] Fang H, Zhang Y, Yang Q C, Lu W, Zhou B, Zhou S. Performance testing on warming effect of heat storage-release metal film in Chinese solar greenhouse. Transactions of the CSAE, 2015; 31(15): 177-182. (in Chinese)

[6] Zhou S, Zhang Y, Cheng R F, Yang Q C, Fang H, Zhou B, et al. Evaluation on heat preservation effects in micro-environment of large-scale greenhouse with active heat storage system. Transactions of the CSAE, 2016; 32(6): 218-225. (in Chinese)

[7] Ling H S, Chen W, Chen Z G, Ma C W, Guan Y, Li N. Performance of phase change material wall with vertical air channels integrating solar concentrators. Transactions of the CSAM, 2015; 46(3): 336-343. (in Chinese)

[8] Liu C X, Ma C W, Wang P Z, Zhao S M, Cheng J Y, Wang M L. Theoretical analysis and experimental verification of heat transfer through thick covering materials of solar greenhouse. Transactions of the CSAE, 2015; 31(2): 170-176. (in Chinese)

[9] Liu C X, Ma C W, Wang P Z, Zhao S M, Cheng J Y, Wang M L. Analysis on affecting factors of heat preservation properties for thermal insulation covers. Transactions of the CSAE, 2015; 31(20): 186-193. (in Chinese)

[10] Chen Q Y. Progress of practice and theory in sunlight greenhouse. Journal of Shanghai Jiao Tong University: Agricultural Science, 2008; 26(5): 343-350. (in Chinese)

[11] Tong G H, David C, Li T L, Wang T. Passive solar energy utilization: A review of cross-section building parameter selection for Chinese solar greenhouses. Renewable \& Sustainable Energy Reviews, 2013(26): 540-548.

[12] Ma C W, Bu Y L, Ji X H, Lu H, Zou L, Wang Y, et al. Method for calculation of heat release at night and evaluation for performance of heat preservation of wall in solar greenhouse. Journal of Shanghai Jiao Tong University: Agricultural Science, 2008; 26(5): 411-415. (in Chinese)

[13] Jin X H, Zou Z R, Zhao X. The span effect on montanic solar greenhouse Journal of Agricultural Mechanization Research, 2015; 37(2): 146-150. (in Chinese)

[14] Wu G F, Huang H Y, Sun E H, Xu Y D, Chen F H, Chang Z Z. Thermal insulation performances of straw bale wall and soil wall in greenhouse. Jiangsu Journal of Agricultural Sciences, 2015; 31(2): 441-448. (in Chinese)

[15] Zhang Y, Gao W B, Zou Z R. Performance experiment and CFD simulation of heat exchange in solar greenhouse with active thermal storage back-wall. Transactions of the CSAE, 2015; 31(5): 203-211. (in Chinese)

[16] Heng T, Jiang J J. Temperature field variation law on building envelope defect by infrared thermal imager. Building Energy Efficiency, 2015; 43(6): 110-114. (in Chinese)

[17] Fox M, Coley D, Goodhew S, de Wilde P. Thermography methodologies for detecting energy related building defects. Renewable and Sustainable Energy Reviews, 2014(40): 296-310.

[18] Lu J, Wang F T, Tang J, Luo B. Online automatic recognition and diagnosis of electrical devices via thermal panorama. Computer \& Modernization, 2015; 2015(8): 19-23. (in Chinese) 
[19] Qi Q Y, Chen C Q, Guo J R, Lai X P. Application of thermal infrared technology in traditional Chinese medicine diagnosis. World Science \& Technology, 2011; 13(6): 1027-1031. (in Chinese)

[20] Yang L P. Study on detecting thermal defects of building envelope by infrared thermal imaging. Master dissertation. Xi'an: Xi'an University of Architecture and Technology, 2010, 05, 113p. (in Chinese)

[21] Rathod H, Gupta R. Sub-surface simulated damage detection using Non-Destructive Testing Techniques in reinforced-concrete slabs. Construction and Building Materials, 2019; 215: 754-764.

[22] Liu X Y, Guo S, Zhao H Q, Liu L J, Li Y M. Study of judging method on thermodynamic disfigurement of pipeline insulation structure. Science
Technology \& Engineering, 2011; 31(11): 7785-7788. (in Chinese)

[23] Wang Z H, Zhao H Q, Liu X Y, Yan S C. Influence of thermodynamic disfigurement of insulation structure on pipeline heat loss. Energy Conservation Technology, 2013; 31(1): 60-62, 88. (in Chinese)

[24] Cao Y F, Bao E C, Zou Z R, He B, Xu W J, An K P, et al. Method for measuring thermodynamic disfigurement area in Chinese solar greenhouse by utilizing thermal infrared image. Transactions of the CSAE, 2016; 32(24): 206-211. (in Chinese)

[25] Meng L L, Yang Q C, Gerard P A B, Wang N. Visual simulation mode for thermal environment in Chinese solar greenhouse. Transactions of the CSAE, 2009; 25(1): 164-170. (in Chinese) 